\title{
Facile Fabrication of Flexible Electrodes and Immobilization of Silver Nanoparticles on Nanoscale Silicate Platelets to Form Highly Conductive Nanohybrid Films for Wearable Electronic Devices
}

\author{
Peng-Yang Huang ${ }^{1}$, Chih-Wei Chiu ${ }^{2, *} \mathbb{0}$, Chen-Yang Huang ${ }^{2}$, Sheng-Yen Shen ${ }^{1}$, Yen-Chen Lee ${ }^{2}$, \\ Chih-Chia Cheng ${ }^{3}$, Ru-Jong Jeng ${ }^{1, *(1)}$ and Jiang-Jen Lin ${ }^{4, *}$ \\ 1 Institute of Polymer Science and Engineering, National Taiwan University, Taipei 10617, Taiwan; \\ d02549006@ntu.edu.tw (P.-Y.H.); reggieshen7@gmail.com (S.-Y.S.) \\ 2 Department of Materials Science and Engineering, National Taiwan University of Science and Technology, \\ Taipei 10607, Taiwan; d10504015@gapps.ntust.edu.tw (C.-Y.H.); d10404013@mail.ntust.edu.tw (Y.-C.L.) \\ 3 Graduate Institute of Applied Science and Technology, National Taiwan University of Science and \\ Technology, Taipei 10607, Taiwan; cccheng@mail.ntust.edu.tw \\ 4 Department of Materials Science and Engineering, National Chung Hsing University, \\ Taichung 40227, Taiwan \\ * Correspondence: cwchiu@mail.ntust.edu.tw (C.-W.C.); rujong@ntu.edu.tw (R.-J.J.); \\ jianglin@ntu.edu.tw (J.-J.L.); Tel.: +886-2-2737-6521 (C.-W.C.); +886-2-3366-5884 (R.-J.J.); \\ +886-2-3366-5312 (J.-J.L.)
}

Received: 10 December 2019; Accepted: 24 December 2019; Published: 27 December 2019

\begin{abstract}
This study investigated films with remarkably high electrical conductivity after they were easily prepared from organic/inorganic nanohybrid solutions containing an organic polymeric dispersant and two-dimensional nanoscale silicate platelets as the inorganic stabilizer dispersed with silver nanoparticles. Transmission electron microscopy shows that the production of silver nanoparticles synthesized by the in situ chemical reduction of $\mathrm{AgNO}_{3}$ in an aqueous solution by $\mathrm{N}, \mathrm{N}$-dimethylformamide results in an average silver nanoparticle diameter of circa $20 \mathrm{~nm}$. Thin films of silver nanoparticles were prepared on a 1- $\mu \mathrm{m}$-thick film with a low sheet resistance of $8.24 \times 10^{-4} \Omega / \mathrm{sq}$, achieved through the surface migration of silver nanoparticles and prepared by sintering at $300{ }^{\circ} \mathrm{C}$ to form an interconnected network. This was achieved with a silver nanoparticle content of $5 \mathrm{wt} \%$, using nanoscale silicate platelets/polyoxyethylene-segmented polyimide/ $/ \mathrm{AgNO}_{3}$ at a weight ratio of 1:10:35. During sintering, the color of the hybrid film changed from gold to milky white, suggesting the migration of silver nanoparticles and the formation of an interconnected network. The results show promise for the fabrication of novel silver-based electrocardiogram electrodes and a flexible wireless electrocardiogram measurement system for wearable electronics.
\end{abstract}

Keywords: silicate nanoplatelets; silver nanoparticles; dispersion; nanohybrid film; electrical conductivity; electrocardiogram

\section{Introduction}

Wearable electronic devices, capable of monitoring motion, heart rate, blood pressure, wrist pulse, and other health-related parameters are an integral part of healthcare [1,2]. Cardiovascular disease is among the leading causes of death worldwide and accounts for more than half of all non-communicable disease fatalities [3]. In order to provide treatment, patients are often monitored using medical electrocardiography (ECG) [4]. The ECG waveform shows the electrical activity of the 
heart and can detect heart irregularities. In order to fabricate sensor devices that transmit physiological signals, studies have explored the use of silver fibers [5], stainless steel [6], intrinsically conductive polymers [7], carbon-based nanomaterials [8], and other nanomaterials for use as electrodes [9,10]. These devices, based on the immobilization of silver nanoparticles, can sense physiological signals in the human body [11]. Reducing organic substrate-based compounds and their use in fabricating nanostructured materials is well-documented for the synthesis of $\mathrm{Cu}[12,13], \mathrm{Fe}[14,15]$, and $\mathrm{Ag}[16,17]$ nanoparticles. In response to the growing interest in wearable electronic devices, and to assure the dispersion of nanoscale particles in solution, a suitable stabilizing agent is needed [18]. Bulk silver materials are commonly utilized in the microelectronics industry due to their low sheet resistance [19]. However, it is arduous to prepare Ag-coated substrate films with an electrical resistance as low as $10^{-2} \Omega / \mathrm{sq}$ [20] due to their unstable electrical characteristics. Therefore, temperatures higher than $300{ }^{\circ} \mathrm{C}$ are necessary during operation of power electronics coated with $\mathrm{Ag}$ films; providing scope for improvement in performance and viability of Ag films through the development of new Ag-coated functional materials [21,22].

Synthesizing silver nanoparticles (AgNPs) using inorganic stabilizing agents such as $\mathrm{Cu}$ [23], Sn [24], carbon nanotubes [25], $\mathrm{Al}_{2} \mathrm{O}_{3}[26]$, and layered silicate clay $[27,28]$ are approaches that avoid the use of organic components. Achieving a low-temperature melting point of the particles was a promising development, made possible due to the sintering properties of AgNPs on the surface of clay platelets [29]. Exfoliated silicate platelets with active plate-chips can exhibit highly charged ions suitable for attracting with AgNPs. The direct exfoliation process of layered $\mathrm{Na}^{+}-\mathrm{MMT}$ by a polyamine salt ion-exchange reaction [30] Pinvolves the isolation of clay nanoplatelets and results in a material with a width of $100 \mathrm{~nm}$ and a thickness of $1 \mathrm{~nm}$ [31]. These platelet-like nanosheets, which possess surface functionalities due to surface charges constructed of $\equiv \mathrm{SiO}^{-} \mathrm{Na}^{+}$, have a high tendency for polar organic and inorganic salts including $\mathrm{AgNO}_{3}[16,29]$. However, it is facile to achieve sheet resistance for transmittance with films, because the low Ag content in these sheets cannot form an interlinked network of AgNPs.

Herein, the manufacture of well-dispersed nanohybrid solutions of AgNPs based on inorganic silicate nanoplatelets and organic polymeric surfactants as hybrid dispersants is studied. The organic surfactant, a polyoxyethylene-segmented polyimide (POE-imide), was prepared from an 4,4'-oxydiphthalic anhydride (ODPA) and polyoxyethylene diamine (POE-amine) by an imidation reaction. The hybrid dispersants of polymeric surfactant and silicate nanoplatelet result in a welldispersed solution of AgNPs. Furthermore, the hybrid dispersion was used to form films, and the melting properties were explored by field-emission scanning electron microscopy. The low-resistance sheet films were successfully fabricated due to Ag melting, thereby enhancing the formation of a continuous Ag interlinked network structure. Thus, a novel silver-based film was fabricated for use in a flexible ECG electrode and a wireless ECG analysis system for wearable electronic devices.

\section{Materials and Methods}

\subsection{Reagents and Chemicals}

Sodium montmorillonite ( $\mathrm{Na}^{+}$-MMT; Nanocor Co., Chicago, IL, USA) is a $\mathrm{Na}^{+}$type of layered aluminosilicate clay with a cationic exchange capacity (CEC) of $115 \mathrm{meq} / 100 \mathrm{~g}$. The 2:1 type of layered silicate clay comprises two tetrahedron sheets sandwiching an edge-shared octahedral sheet, with an average polydisperse dimension of $100 \mathrm{~nm} \times 100 \mathrm{~nm} \times 1 \mathrm{~nm}$ for each sheet and approximately 10 platelets in one stack. The 4,4'-Oxydiphthalic anhydride (ODPA) was purchased from Aldrich Chemical Co., St. Louis, MO, USA, and purified by sublimation. Jeffamine ${ }^{\circledR}$ ED2001 (abbreviated POE-2000), a commercial brand of POE-amine, was purchased from Huntsman Chemical Co., Los Angeles, CA, USA. Silver nitrate $\left(\mathrm{AgNO}_{3}\right.$, purity $\left.99.9 \%\right)$ was purchased from Aldrich Chemical Co., St. Louis, MO, USA, and N,N-dimethylformamide (DMF) from TEDIA Company Inc., Fairfield, OH, USA. 


\subsection{Direct Exfoliation of Layered $\mathrm{Na}^{+}-\mathrm{MMT}$ Clay into Nanoscale Silicate Platelets in Water Suspension}

Previously, characterization of the direct exfoliation of synthetic $\mathrm{Na}^{+}-\mathrm{MMT}$ to obtain exfoliated nanoscale silicate platelets (NSPs) using a polyamine salt has been demonstrated [30-32]. NSPs were dispersed in water and purified by solvent toluene/water extraction. Subsequently, the surface ionic character of the NSPs was determined using a zeta potential analyzer (Zetasizer Nano-Zs90 instrument, Malvern Instrument Ltd., Worcestershire, UK). X-ray powder diffraction (XRD), transmission electron microscopy (TEM), and atomic force microscopy (AFM) were used to investigate which materials could be exfoliated. The ionic NSPs had a measured width of approximately $100 \mathrm{~nm}$ and thickness of $1 \mathrm{~nm}$.

\subsection{Synthesis of the Poly(oxyethelene)-Segmented Amide-Imide}

A poly(oxyethelene)-segmented amide-imide was synthesized by the amidation and following imidation of ODPA and POE-2000 in a molar ratio of 5:6 (Scheme 1). For this, $10 \mathrm{~g}$ of $0.005 \mathrm{~mol}$ POE-2000 in $15 \mathrm{~mL}$ tetrahydrofuran was transferred to a $150 \mathrm{~mL}$ three-neck round-bottom flask equipped with a thermometer, a mechanical stirrer, and nitrogen outlet/inlet line. Next, $1.29 \mathrm{~g}$ of 0.004 mol solution of ODPA dispersed in $12 \mathrm{~mL}$ tetrahydrofuran was added dropwise to the flask through an addition pipe with vigorous stirring and maintained at a temperature of $25^{\circ} \mathrm{C}$ for $4 \mathrm{~h}$. The product of the reaction was analyzed via Fourier transform infrared (FTIR) spectroscopy, showing characteristic absorption peaks at $1572 \mathrm{~cm}^{-1}$ and $1647 \mathrm{~cm}^{-1}$ for the amido acid functionalities (Figure 1). Major absorption peaks were detected for cyclized imide functionalities at $1713 \mathrm{~cm}^{-1}$ and $1770 \mathrm{~cm}^{-1}$, after increasing temperature to $180{ }^{\circ} \mathrm{C}$ for $4 \mathrm{~h}$. The peaks, which indicated a significant conversion of POE-imide, had different characteristics. A yellow solid was recovered after the product solution underwent rotary evaporation.

$\mathbf{n}$<smiles>O=C1OC(=O)c2cc(Oc3ccc4c(c3)C(=O)OC4=O)ccc21</smiles>

4,4'-Oxydiphthalic anhydride (ODPA, $M_{w}=310 \mathrm{~g} / \mathrm{mol}$ ) $+(n+1)$

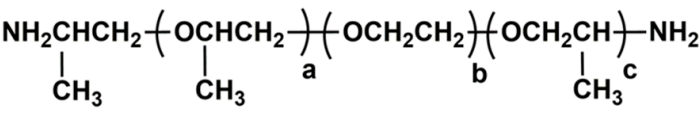

Poly(oxyethylene)-diamine $\left(P O E-2000, a+c=6, b=39, M_{w}=2,000 \mathrm{~g} / \mathrm{mol}\right)$

$25^{\circ} \mathrm{C}, 4 \mathrm{~h}$

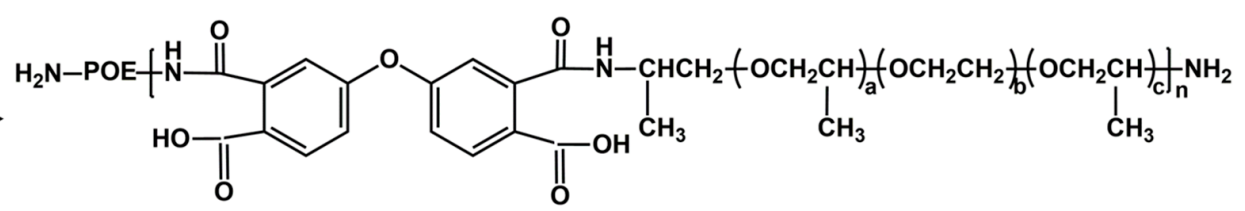

Poly(oxyethylene)-segmented amidoacid (POE-amidoacid)

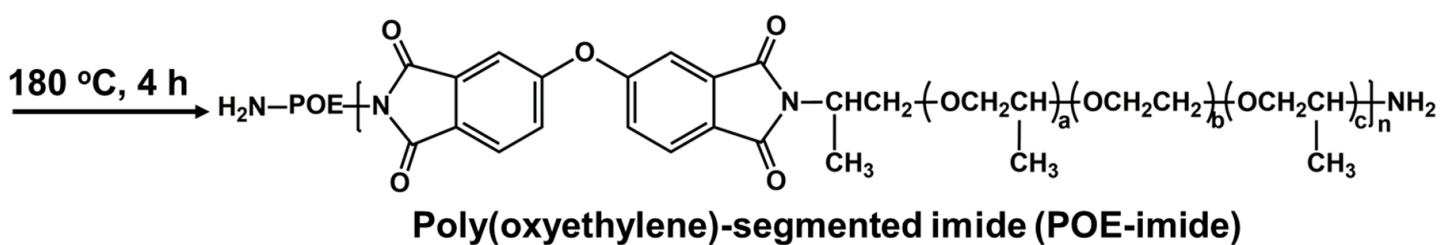

Scheme 1. Synthetic scheme for converting 4,4'-oxydiphthalic anhydride and poly(oxyethylene)-diamine to the poly(oxyethylene alkylene)-segmented amido acid and imide (polyoxyethylene-(POE)-derived amido acid and imide) as polymeric dispersants. 


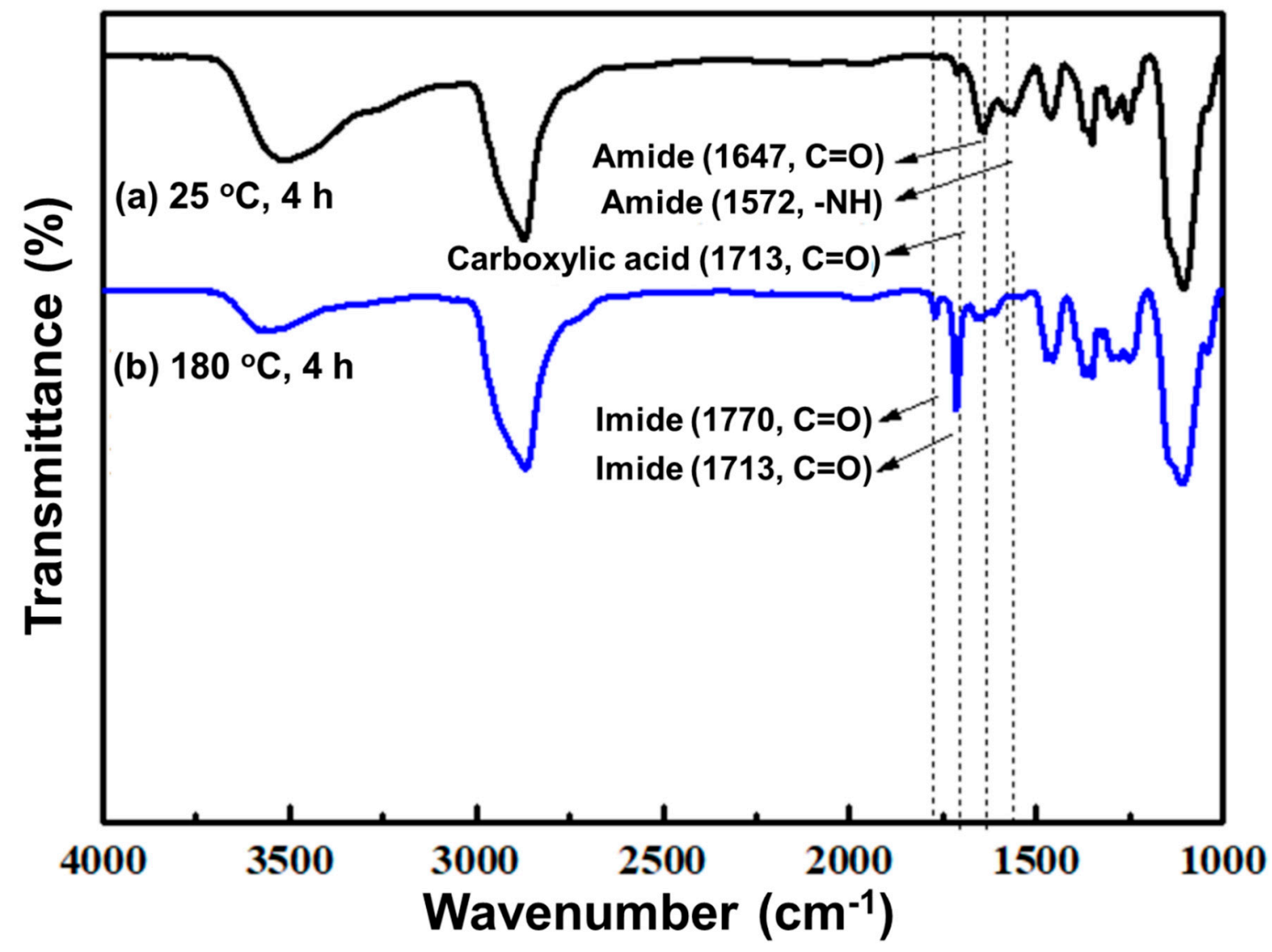

Figure 1. Fourier transform infrared (FTIR) spectra of POE-derived dispersants of (a) POE-amido acid intermediate and (b) POE-imide from amido acid to cyclized imide functionalities.

\subsection{Preparation of NSP/POE-Imide/AgNP Nanohybrid Suspensions}

The NSP slurry $(0.025 \mathrm{wt} \%$ of NSP) was dispersed in $5 \mathrm{~g}$ of water in a $50 \mathrm{~mL}$ volumetric flask and left at an ambient temperature for $10 \mathrm{~min}$; similarly, $0.25 \mathrm{~g}$ of POE-imide was dispersed in $5 \mathrm{~g}$ of DMF. Next, the NSP and POE-imide solutions were mixed, followed by the addition of $\mathrm{AgNO}_{3}$ $(1.49 \mathrm{~g}, 5 \mathrm{wt} \%)$. The temperature was maintained at $80^{\circ} \mathrm{C}$ for $4 \mathrm{~h}$ and stirred. Color changes from yellow-brown to dark golden were visually assessed as a function of temperature; the suspension was analyzed using a UV-Vis spectrophotometer, which suggested the reduction of $\mathrm{Ag}^{+}$to $\mathrm{Ag}^{0}$ when the color changed from white to yellow. A homogeneous suspension was observed in solutions of $\mathrm{AgNO}_{3}$, POE-imide, and NSP, as well as sintering processes that were unique to nanoparticles. In addition, a control experiment using POE-imide stabilized homogenous colloidal AgNP solution was conducted. The UV absorption spectra of the various suspensions were observed using $0.2 \mathrm{~g}$ of the samples in $5.0 \mathrm{~g}$ of distilled water. Transmission electron microscopy (TEM) images were acquired for further analysis.

\subsection{Preparation of NSP/POE-Imide/AgNP Nanohybrid Films}

The film was attached to a polyimide substrate of area $2 \times 2 \mathrm{~cm}$. The dripping solution of the nanohybrid solution was attached on a piece of the substrate via high-temperature sintering and then placed in a convection oven. The sintering programs were set to $80^{\circ} \mathrm{C}, 160^{\circ} \mathrm{C}, 250^{\circ} \mathrm{C}$, and $300^{\circ} \mathrm{C}$ for $0.5 \mathrm{~h}$ each prior to use.

\subsection{Instrumental Characterization}

Fourier transform infrared spectroscopy (FTIR) was carried out on a Perkin-Elmer Spectrum One FTIR Spectrometer (PerkinElmer Inc., Waltham, MA, USA) between $4000-400 \mathrm{~cm}^{-1}$. The 
POE-imide dispersants were prepared by dissolving in ethanol, followed by evaporation on a $\mathrm{KBr}$ plate resulting in a thin film. The UV-Vis spectra of the AgNP suspension was measured using a Shimadzu UV-2450 spectrophotometer (Shimadzu Co. Ltd., Tokyo, Japan). TEM images were observed using a Zeiss EM 902A field emission microscope (Carl Zeiss Microscopy GmbH, Oberkochen, Germany) at an accelerating voltage of $80 \mathrm{kV}$. Field emission scanning electron microscopy (FE-SEM) images were observed using a JEOL JSM-6700F scanning electron microscope (JEOL, Tokyo, Japan) operating at an accelerating voltage of $80 \mathrm{kV}$. The sample substrates were mounted on a sample holder using adhesive carbon tape. Elemental analyses of the film measurements were conducted using energy-dispersive X-ray spectroscopy (EDX, Oxford INCA Energy 400, Oxford Instrument plc, Abingdon, UK). Thermogravimetric analysis (TGA), was conducted on a Perkin-Elmer Pyris 1 instrument. The organic/inorganic weight ratio was estimated from the weight losses by ramping the temperature from 100 to $500{ }^{\circ} \mathrm{C}$ at the rate of $20^{\circ} \mathrm{C} / \mathrm{min}$ in nitrogen. The sheet resistances of the hybrid films containing AgNPs were surveyed with a Keithley 2400 digital source meter (Keithley Instruments, Inc., Cleveland, OH, USA) equipped with a four-point probe. The electrical conductivities of the hybrid films containing AgNPs was measured by utilizing them to illuminate light-emitting diode (LED) lamps with power dissipation at $100 \mathrm{~mW}$ and a peak forward current of $100 \mathrm{~mA}$. Triplicate measurements of the synthesized quantities were performed to confirm reproducibility.

\section{Results and Discussion}

\subsection{Synthesis of NSP/POE-Imide/AgNP Nanohybrid Suspensions}

Nanoscale silicate platelets were fabricated using a two-step process, including the exfoliated agent of layered $\mathrm{Na}^{+}-\mathrm{MMT}$, followed by organic solvent extraction using a water and toluene mixture (Scheme 2) [30-32]. During extraction, the mixture separated into aqueous and organic phases. The upper layer, containing the exfoliated agent organics was evaporated, leaving the lower aqueous layer, which contained the NSP suspension. The nanoplates consisted of 18,000 ions/plate and exhibited ionic interactions arising from the in situ reduction of silver nitrate used in the synthesis of AgNPs. The AgNPs were placed onto both the NSP and the polymeric dispersant because of their superior non-covalent ionic interactions and van der Waals force. Species possessing mutual attraction through non-covalent interactions were needed so that the two nanomaterials successfully engineered a substrate for the electrostatic attraction between the AgNPs and NSPs. Additionally, there is a partial negative charge in the suspension from the ether functional group of the POE $\left(-\mathrm{CH}_{2} \mathrm{CH}_{2} \mathrm{O}-\right) \mathrm{R}_{\mathrm{x}} \mathrm{R}$ block fabricated on POE-imide/AgNPs.

Key to this synthesis is the binding of $\mathrm{Ag}^{+}$ions to the ionic NSP surface and the polyoxyethylene backbone amine, which proceeds through the chemical reduction of DMF and simultaneous reduction of $\mathrm{Ag}^{+}$to $\mathrm{Ag}^{0}$. DMF can be used as a reducing agent for converting $\mathrm{Ag}^{+}$to $\mathrm{Ag}^{0}$ for the in situ chemical synthesis of AgNPs when the dispersing POE-imide/NSP are sealed in a $\mathrm{H}_{2} \mathrm{O} / \mathrm{DMF}$ co-solvent $[16,21]$. Samples with varied weight ratios were analyzed, and the color change was detected with UV-Vis spectroscopy (Figure 2a). NSP/POE-imide/ $\mathrm{AgNO}_{3}$ was prepared in weight ratios of 1:10:10, 1:20:20, 1:20:10, and 0:1:1. A characteristic absorption peak at $440 \mathrm{~nm}$ for the NSP/POE-imide/AgNO 3 dispersion indicated a homogeneous mixture. In the control experiment, a POE-imide surfactant was utilized as the stabilizer instead of NSP/POE-imide. The product solution exhibited an absorption peak at approximately $446 \mathrm{~nm}$ when the $\mathrm{POE}-i m i d e / \mathrm{AgNO}_{3}$ weight ratio was maintained at $1: 1$. Figure $2 \mathrm{~b}$ shows TEM images showing the size distribution of formed AgNPs. The AgNPs are well-dispersed on the surface of the platelets with a particle diameter of approximately $10-20 \mathrm{~nm}$. During the reduction of $\mathrm{AgNO}_{3}$, the surface of the silicate sheets and the polymer chains adhere together when the AgNPs were generated and decreased simultaneously in size. The average size of the AgNPs decreased due to the increasing number of NSPs added to the system. The hybrid dispersants showed excellent homogeneity and remained stable for three months. 


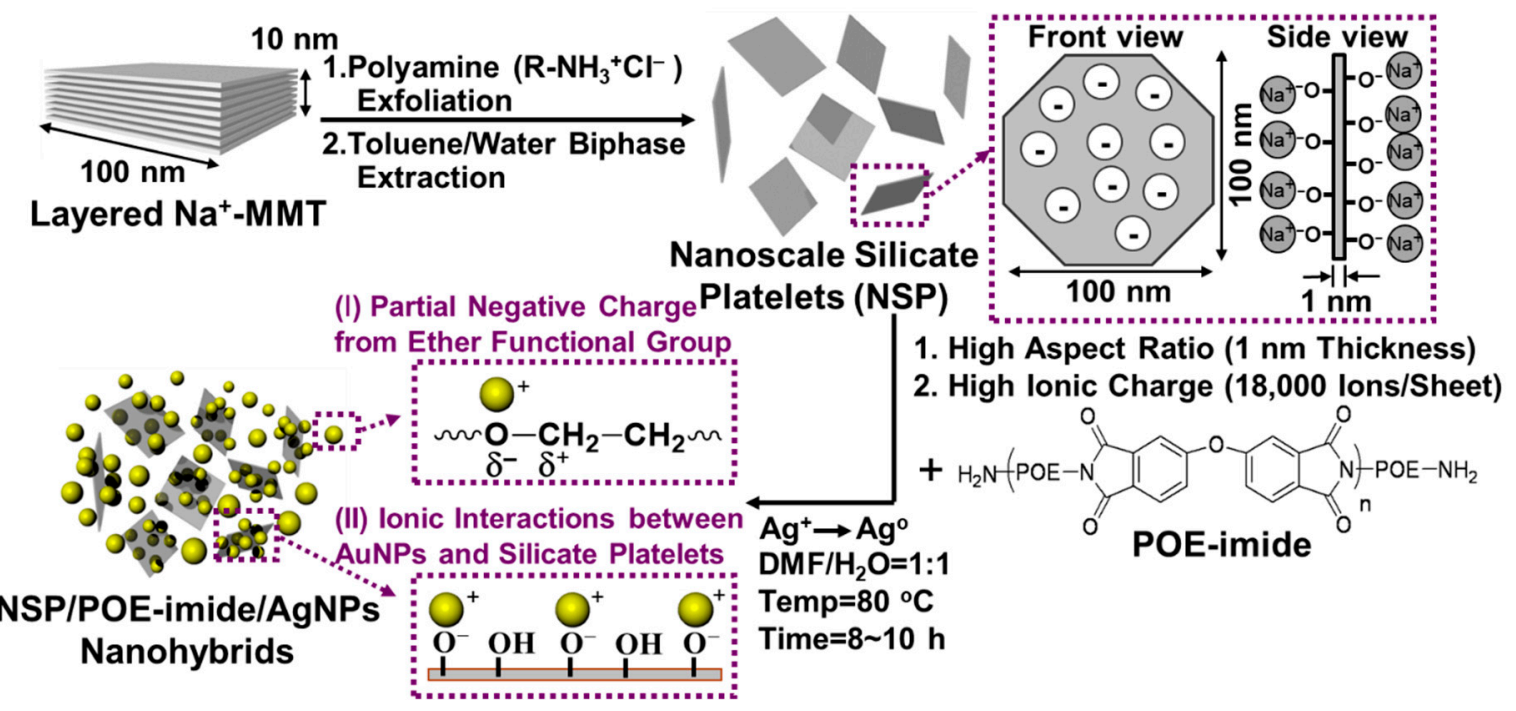

Scheme 2. Schematic of the exfoliation process for the layered $\mathrm{Na}^{+}-\mathrm{MMT}$ clay into exfoliated silicate nanosheets and illustration of the surface ionic charges. The polymeric dispersant and silicate are attracted to $\mathrm{Ag}^{+}$ions, resulting in well-dispersed AgNPs. A schematic of the dispersion mechanisms of the AgNPs/nanoscale silicate platelets (NSPs) and AgNPs/POE-imide stabilizations are also shown.
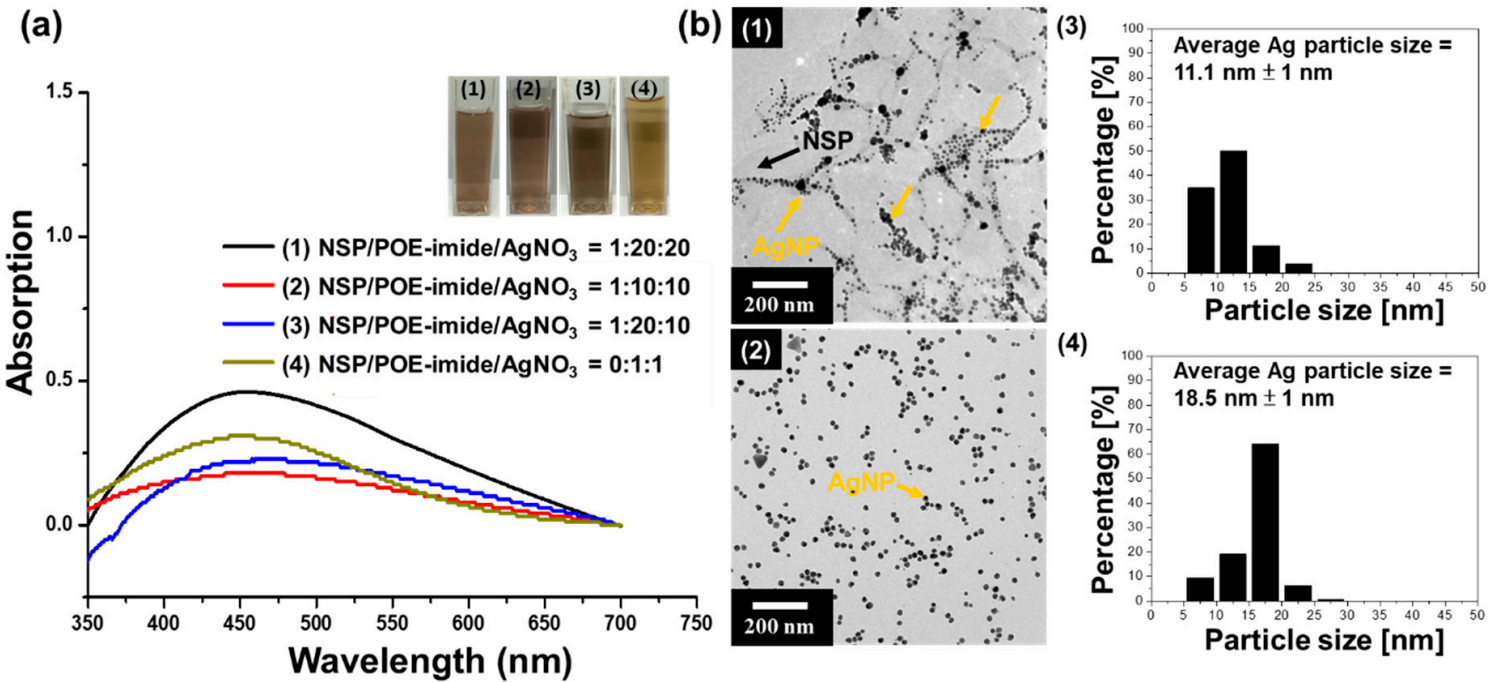

Figure 2. (a) UV-Vis absorption spectra of AgNPs suspension with various weight fractions of POE-imide and NSP. Inset: NSP/POE-imide/AgNO 3 reductions with weight ratios of (1) 1:20:20, (2) 1:10:10, (3) 1:20:10, and (4) 0:1:1. (b) TEM images of NSP/POE-imide/AgNO 3 with weight ratios of (1) 1:20:20 and (2) 0:1:1. Histograms of the Ag particle sizes, determined from TEM images of NSP/POE-imide/AgNO 3 with weight ratios of (3) 1:20:20 and (4) 0:1:1.

\subsection{Facile Fabrication of the Highly Conductive NSP/POE-Imide/AgNPs Nanohybrid Films}

Thermogravimetric analysis (TGA) was conducted in the temperature range $100-500{ }^{\circ} \mathrm{C}$ at a heating rate of $20^{\circ} \mathrm{C} / \mathrm{min}$ in nitrogen (Figure 3a). The TGA trace indicated thermal degradation at sintering temperatures of $180{ }^{\circ} \mathrm{C}, 200{ }^{\circ} \mathrm{C}$, and $250{ }^{\circ} \mathrm{C}$. It also indicated the weight ratios of the non-exfoliated and exfoliated clay control samples. NSP/POE-imide/AgNPs hybrid samples with weight ratios of 1:0:0, 0:1:0, 0:1:1, and 1:10:35 (5 $\mathrm{wt} \%)$ were prepared through sintering treatments at different temperatures. Furthermore, the dispersion of the AgNPs/POE-imide/NSP hybrid material was coated on a polyimide substrate and subjected to a succession of heat treatments $\left(80^{\circ} \mathrm{C}, 160^{\circ} \mathrm{C}\right.$, $200{ }^{\circ} \mathrm{C}$, and $300^{\circ} \mathrm{C}$ for $0.5 \mathrm{~h}$ each). The appearance of the film product indicated that the AgNPs had 
moved to the surface of the NSP and had agglomerated, forming an interconnected network structure. This was accompanied by a change in film surface color-from gold to milky white (Figure $3 b$ (1) and (2)). The role of silicate platelets is to generate paths for directing the migration of AgNPs into the surface. However, some AgNPs attached to the silicate surface at $300{ }^{\circ} \mathrm{C}$, as evidenced by the high conductivity. The electrical resistance of the sintered films was measured by using the films in an electrical circuit to illuminate LED bulbs (Figure 3c (1) and (2)) and Supplementary Material Video S1). Furthermore, the flexible duration and simultaneous conductance changes were tested under 3000 cycles (Figure 3d,e, and Supplementary Material Video S1). The electrical performance of the films showed a different trend for the POE-imide contents than that observed for the resistivity of the silver features. After heat treatment at $300{ }^{\circ} \mathrm{C}$, the sheet resistance of the NSP/POE-imide/AgNO $\mathrm{Ag}_{3}$ hybrid film with a weight ratio of 1:20:20 varied by over eight orders of magnitude compared to that of the hybrid film with a weight ratio of 1:0:0 (the respective sheet resistances were $1.94 \times 10^{6} \Omega / \mathrm{sq}$ and $5.32 \times 10^{-2} \Omega / \mathrm{sq}$ ), suggesting that the sheet resistance varied according to the AgNP content. A decrease of the POE-imide content (NSP/POE-imide/AgNO $1: 10: 20$ ) led to a sheet resistance of $5.56 \times$ $10^{-2} \Omega / \mathrm{sq}$ when the sintering temperature was $300{ }^{\circ} \mathrm{C}$. The sheet resistance decreased to $10^{-4} \Omega / \mathrm{sq}$ when the AgNP content increased to $5 \mathrm{wt} \%$ (NSP/POE-imide/AgNO $\mathrm{AN}_{3}$ 1:10:35) for the same temperature (Table 1). The variation in the sheet resistance shows that the conductivity of the nanohybrid materials was improved when AgNPs were used as conductive fillers.

(a)
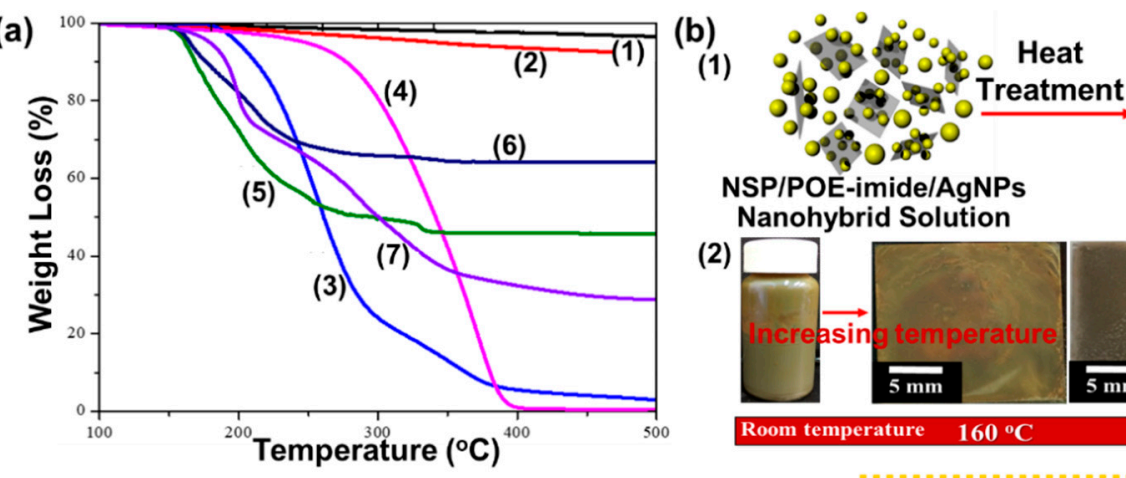

Nanohybrid Solution
Nan

(2)

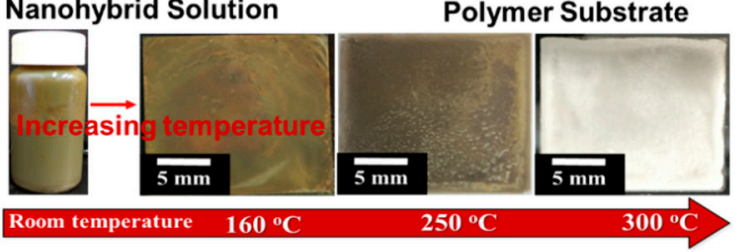

(c) (1)
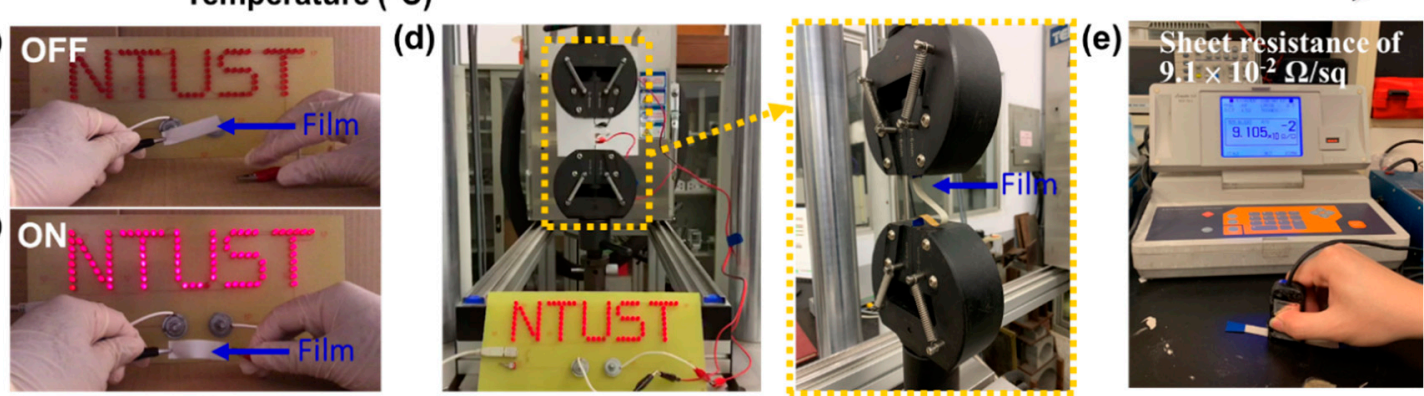

Figure 3. (a) Thermogravimetric analysis (TGA) curves and relative thermo-oxidative stability of the NSP/POE-imide/AgNPs nanohybrid films with different weight ratios in air. (1) $\mathrm{Na}^{+}-\mathrm{MMT}$ (non-exfoliation), (2) NSP (exfoliation), (3) POE-imide (organic dispersant), (4) POE-imide nanohybrid with NSP (exfoliation), (5) POE-imide nanohybrid with AgNP/NSP (exfoliation) in $5 \mathrm{wt} \%$, (6) POE-imide nanohybrid with AgNP/NSP (exfoliation) in $8 \mathrm{wt} \%$, and (7) AgNP/POE-imide. (b) Colored films were observed (1) schematic diagram showing the migration of AgNPs to the film surface, (2) demonstration of AgNP migration to surface and its melting to achieve white color while heating NSP/POE-imide/AgNPs. (c) (1 and 2) Demonstration of electrode behavior by switching LED bulbs OFF and ON of NSP/POE-imide/AgNPs films with weight ratio of 1:20:20, which have been heated to $300{ }^{\circ} \mathrm{C}$. (d) The mechanical stability of flexible electrodes was tested for a flexible duration under 3000 cycles. (e) The result showed that the sheet resistance of hybrid films is maintained by at least $10^{-2} \Omega /$ sq after a durability test. 
Table 1. Summary of sheet resistances of the NSP/POE-imide/AgNP nanohybrid films.

\begin{tabular}{|c|c|c|c|c|c|}
\hline \multirow{2}{*}{ Sample } & \multirow{2}{*}{$\begin{array}{l}\text { Weight Fraction } \\
\qquad(w / w / w)\end{array}$} & \multirow{2}{*}{$\begin{array}{l}\operatorname{AgNP}{ }^{a} \\
\left(w_{t} \%\right)\end{array}$} & \multicolumn{3}{|c|}{ Sheet Resistance $(\Omega / s q){ }^{b}$} \\
\hline & & & $160^{\circ} \mathrm{C}$ & $250{ }^{\circ} \mathrm{C}$ & $300^{\circ} \mathrm{C}$ \\
\hline NSP & - & - & - & - & $1.94 \times 10^{6}$ \\
\hline POE-imide $/ \mathrm{AgNO}_{3}$ & $1: 1$ & - & - & $1.45 \times 10^{-1}$ & $2.68 \times 10^{-2}$ \\
\hline \multirow{4}{*}{ NSP/POE-imide/ $/ \mathrm{AgNO}_{3}$} & 1:10:10 & 1 & $8.27 \times 10^{1}$ & $6.26 \times 10^{-2}$ & $5.27 \times 10^{-2}$ \\
\hline & $1: 20: 20$ & 1 & $2.74 \times 10^{6}$ & $2.34 \times 10^{3}$ & $5.32 \times 10^{-2}$ \\
\hline & $1: 10: 20$ & 1 & - & $4.45 \times 10^{-2}$ & $5.56 \times 10^{-2}$ \\
\hline & 1:10:35 & 5 & $2.76 \times 10^{3}$ & $4.12 \times 10^{-4}$ & $8.24 \times 10^{-4}$ \\
\hline
\end{tabular}

${ }^{a}$ AgNP content in suspension. ${ }^{b}$ The suspension was coated on a polyimide substrate and the sheet resistance was measured using a four-point probe.

\subsection{Observation of Interconnected Network of Melted AgNPs via FE-SEM}

Field emission scanning electron microscopy images of nanohybrid films with sintering temperatures of $160{ }^{\circ} \mathrm{C}, 250^{\circ} \mathrm{C}$, and $300^{\circ} \mathrm{C}$ were obtained (Figure 4a). A homogeneous size distribution and a low surface energy was observed on the NSP sheets of AgNPs. The AgNPs can be seen moving to the surface of the NSP and aggregating into lumps as the temperature increased from $160^{\circ} \mathrm{C}$ to $300{ }^{\circ} \mathrm{C}$. A continuous network was observed when the AgNPs melted at $300^{\circ} \mathrm{C}$; this contributed to enhancing the conductivity of the nanohybrid materials. Furthermore, the cross-section of the hybrid films shows a layer-by-layer structure of silicate platelets, suggesting the migration of AgNPs to the surface when the temperature reached $300^{\circ} \mathrm{C}$ (Figure $4 \mathrm{~b}$ (1)). Energy dispersive spectroscopy (EDS) analysis of the hybrid films confirmed that they consisted of Ag and NSP (Figure 4b (2)). Degradation of the organic dispersant appeared to be completed at a temperature of $300{ }^{\circ} \mathrm{C}$; furthermore, it can be shown that the interconnected network of AgNPs is formed due to the sintering temperature. Thus, the AgNPs were melted by selecting hybrid films of appropriate conductivity.

(a)
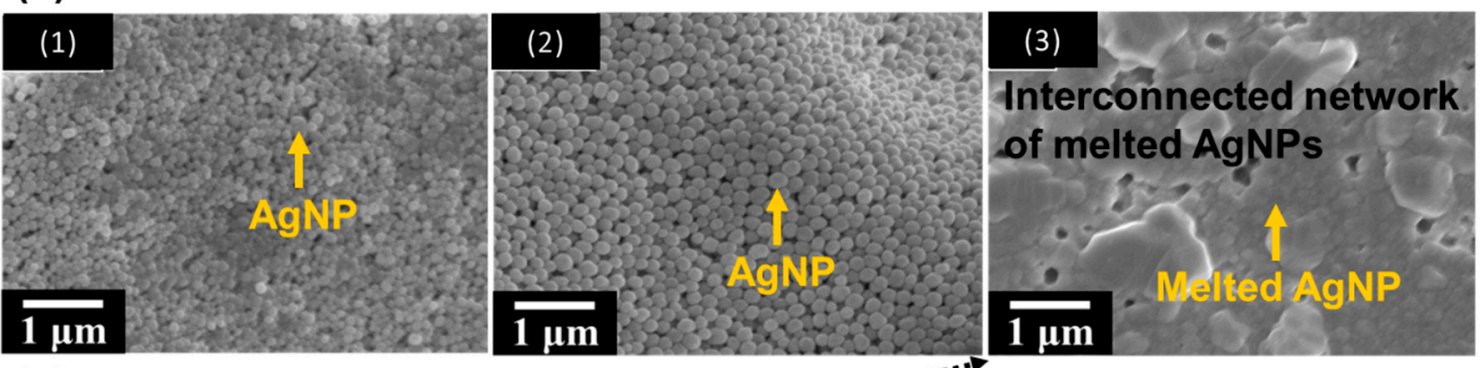

(b)
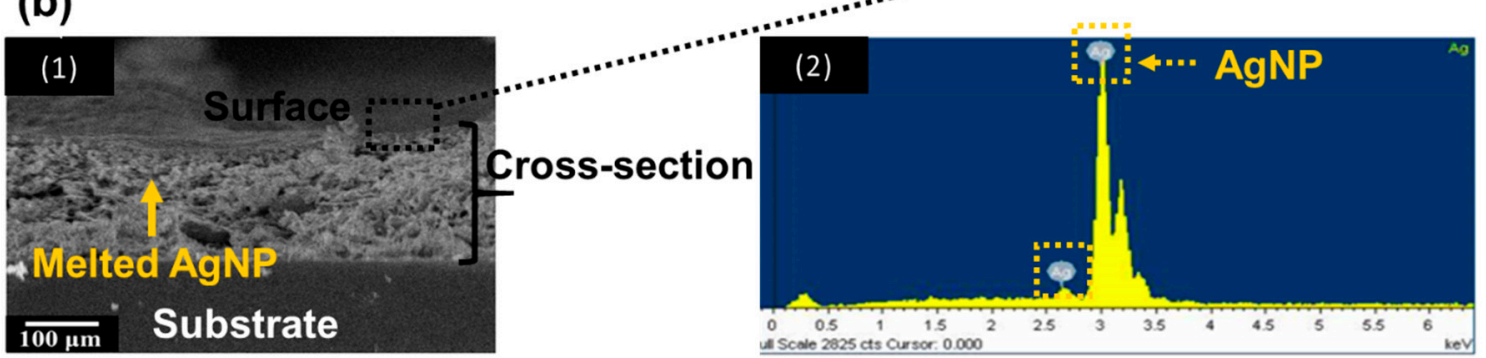

Figure 4. (a) Field emission scanning electron microscopy (FE-SEM) images of NSP/POE-imide/AgNP nanohybrid films with a weight ratio of 1:10:35 with $5 \mathrm{wt} \%$ AgNPs in solution and heat-treated at (1) $160{ }^{\circ} \mathrm{C}$, (2) $250{ }^{\circ} \mathrm{C}$, and (3) $300{ }^{\circ} \mathrm{C}$ for $0.5 \mathrm{~h}$ each. (b) (1) Cross-sectional view of nanohybrid film. (2) EDS profiles of the NSP/POE-imide/AgNP nanohybrid films with a weight ratio of 1:10:35 after heating at $300{ }^{\circ} \mathrm{C}$. 


\subsection{Measurements of ECG Signals}

Electrocardiogram signals were measured from fabricated silver-based electrodes via an ECG acquisition system (ECG TD3 Device, Yang Yin Co. Ltd., Taipei, Taiwan) using manufactured smart clothing to detect measurements from two electrodes [33,34]. ECG readings were obtained from a 25-year-old female during pre-exercise, exercise, and post-exercise phases with the electrodes attached to clothing on the upper-body. ECG signals were filtered between frequencies of $0.5 \mathrm{and} 500 \mathrm{~Hz}$ during sample acquisition and amplification by the signal acquisition system. AgNPs were coated onto fiberglass after immersion for $0.5 \mathrm{~h}$ with the following sintering temperature program: $80{ }^{\circ} \mathrm{C}$ for $1 \mathrm{~h}$; $150{ }^{\circ} \mathrm{C}$ for $0.5 \mathrm{~h} ; 250^{\circ} \mathrm{C}$ for $0.5 \mathrm{~h} ; 300^{\circ} \mathrm{C}$ for $0.5 \mathrm{~h}$. The P-wave, QRS-complex, and T-wave were clearly visible in the waveforms. Consequently, the PQRTS waveform was observed at $10 \mathrm{~s}$. The ECG signal response from NSP/POE-imide/AgNPs nanohybrid electrodes can be seen in Figure 5. In comparison with conventional $\mathrm{Ag} / \mathrm{AgCl}$ electrodes, fiberglass displayed remarkable flexibility, exhibiting reliability for use in fiber applications. By monitoring the electron-donor and electron-acceptor molecules in AgNPs, an ECG signal response was measured. It was shown that films with electrode sheet resistances of $8.24 \times 10^{-4} \Omega / \mathrm{sq}$ and annealed at $300{ }^{\circ} \mathrm{C}$ displayed stability signals and had a visible P-wave, QRS-complex, and T-wave. ECGs were conducted before and after exercising. A video showing the high sensitivity of the ECG electrodes using the NSP/POE-imide/AgNPs nanohybrid is provided in the Supplementary Material (Video S1).

(a) 1. Blank Heart Rate Belt

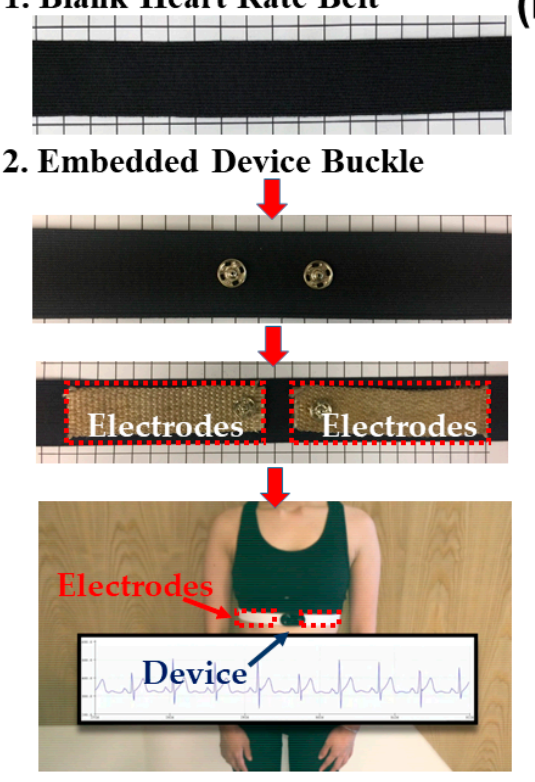

(b)
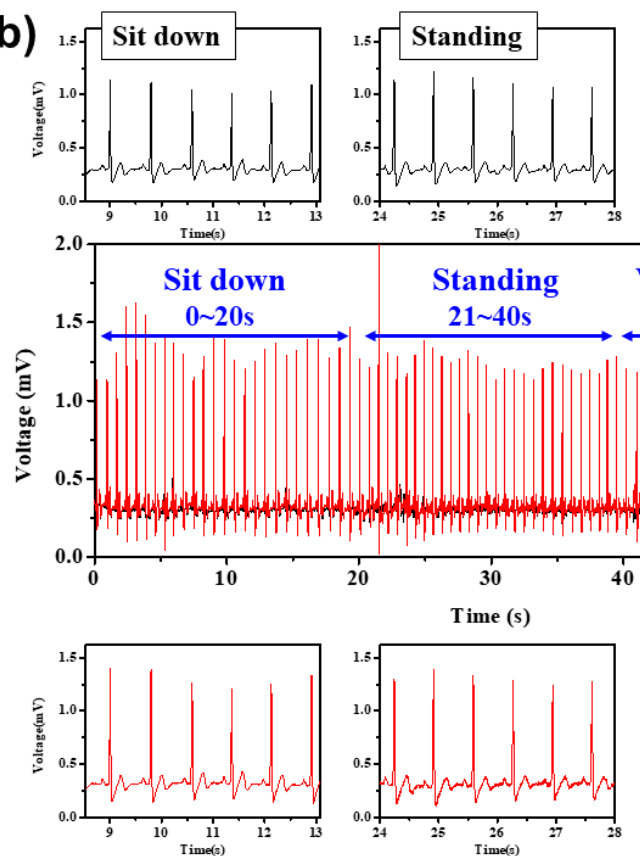

Time (s)

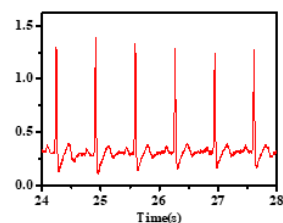

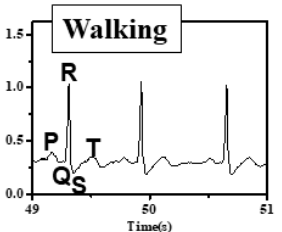

Valling- $\mathbf{A g} / \mathbf{A g C l}$ $1 \sim 60 \mathrm{~s}-300^{\circ} \mathrm{C}$ $41 \sim 60 \mathrm{~s}$
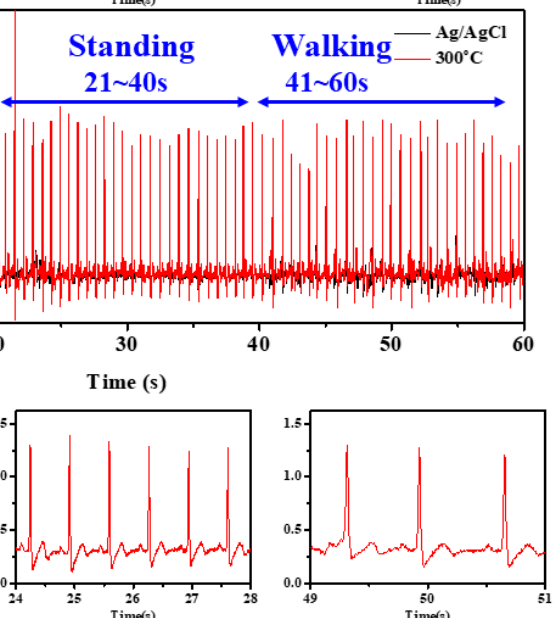

Figure 5. (a) Optical images of heart rate monitor device featuring silver-based electrodes. (b) Magnified view of the measured electrocardiogram (ECG) wave, showing the P-wave, QRS-complex, and T-wave under different conditions.

\section{Conclusions}

Highly sensitive ECG electrodes from electrically conductive films containing NSP/POE-imide/AgNPs nanohybrids were fabricated. The use of POE-imide as an organic dispersant and NSP as an inorganic dispersant allowed AgNPs to be well-dispersed in a DMF/water co-solvent system. The organic dispersant poly(oxyethylene) imide (POE-imide) was synthesized using poly(oxyethylene)-diamine and 4,4'-oxydiphthalic anhydride by amidation and continuous imidation. High aspect ratio polydisperse NSP (width: $100 \mathrm{~nm}$; thickness: $1 \mathrm{~nm}$ ) was prepared by the exfoliation of sodium montmorillonite $\left(\mathrm{Na}^{+}-\mathrm{MMT}\right)$ clay via an ion-exchange reaction with polyamine. The inorganic nanoplatelets possessed 
ionic charges in the form of $\equiv \mathrm{SiO}^{-} \mathrm{Na}^{+}$at $115 \mathrm{meq} / 100 \mathrm{~g}$ and were effective in stabilizing AgNPs formed by the in situ chemical reduction of silver nitrate $\left(\mathrm{AgNO}_{3}\right)$. Through a facile coating and sintering process, hybrid polymer-mediated films could be made that exhibited low surface resistances of up to $10^{-4} \Omega / \mathrm{sq}$. Furthermore, the surface resistance of the hybrid films appeared to decrease due to the interconnected network formed by the AgNP. The results indicate that these films are promising as nano-conductors in electronic devices. Silver-based electrodes show demonstrated potential not only in biosensor ECG systems for monitoring cardiac activity but also functional biological applications. However, exploring the large-scale production of these films is dependent on commercial viability and uptake. The use of dry electrodes for ECG devices is an exciting application for wearable technology featuring nanohybrid films.

Supplementary Materials: The following are available online at http://www.mdpi.com/2079-4991/10/1/65/s1, Video S1: A video showing a demonstration of the LED bulbs illuminated using the highly electrically conductive films and a video depicting a highly sensitive electrocardiogram (ECG) measurement by highly electrically conductive films as flexible electrodes under dynamic activity are provided.

Author Contributions: P.-Y.H. conceived the idea of the paper and wrote the manuscript. C.-W.C., R.-J.J. and J.-J.L. offered advice. P.-Y.H., C.-W.C., C.-Y.H., S.-Y.S., Y.-C.L., C.-C.C., R.-J.J. and J.-J.L. analyzed the data and fully discussed and commented on the paper. All authors have read and agreed to the published version of the manuscript.

Funding: This research was funded by the Ministry of Science and Technology (MOST 105-2221-E-002-003 and MOST 107-2221-E-011-043) of Taiwan.

Conflicts of Interest: The authors declare no conflict of interest.

\section{References}

1. An, B.W.; Shin, J.H.; Kim, S.Y.; Kim, J.; Ji, S.; Park, J.; Lee, Y.; Jang, J.; Park, Y.G.; Cho, E.; et al. Smart sensor systems for wearable electronic devices. Polymers 2017, 9, 303. [CrossRef] [PubMed]

2. Pandian, P.S.; Mohanavelu, K.; Safeer, K.P.; Kotresh, T.M.; Shakunthala, D.T.; Gopal, P.; Padaki, V.C. Smart vest: Wearable multi-parameter remote physiological monitoring system. Med. Eng. Phys. 2008, 30, 466-477. [CrossRef] [PubMed]

3. Celik, N.; Manivannan, N.; Strudwick, A.; Balanchendran, W. Graphene-enabled electrodes for electrocardiogram monitoring. Nanomaterials 2016, 6, 156. [CrossRef] [PubMed]

4. Mcsharry, P.E.; Clifford, G.D.; Tarassenko, L.; Smith, L.A. A dynamical model for generating synthetic electrocardiogram signals. IEEE Trans. Biomed. Eng. 2003, 5, 289-294. [CrossRef] [PubMed]

5. Lee, S.; Shin, S.; Lee, S.; Seo, J.; Son, S.; Cho, H.J.; Algadi, H.; Al-Sayari, S.; Kim, D.E.; Lee, T. Ag nanowire reinforced highly stretchable conductive fibers for wearable electronics. Adv. Funct. Mater. 2015, 25, 3114-3121. [CrossRef]

6. Dong, S.; Han, B.; Ou, J.; Li, Z.; Han, L.; Yu, X. Electrically conductive behaviors and mechanisms of short-cut super-fine stainless wire reinforced reactive powder concrete. Cem. Concr. Compos. 2016, 720, 48-65. [CrossRef]

7. Wei, D.; Cotton, D.; Ryhanen, T. All-solid-state textile batteries made from nano-emulsion conducting polymer inks for wearable electronics. Nanomaterials 2012, 2, 268-274. [CrossRef]

8. Jost, K.; Stenger, D.; Perez, C.R.; Mcdonough, J.K.; Lian, K.; Gogotsi, Y.; Dion, G. Knitted and screen printed carbon-fiber supercapacitors for applications in wearable electronics. Energy Environ. Sci. 2013, 6, 2698-2705. [CrossRef]

9. Su, M.; Li, F.; Chen, S.; Huang, Z.; Qin, M.; Li, W.; Zhang, X.; Song, Y. Nanoparticle based curve arrays for multirecognition flexible electronics. Adv. Mater. 2015, 28, 1369-1374. [CrossRef]

10. Faupel, F.; Zaporojtchenko, V.; Strunskus, T.; Elbahri, M. Metal-polymer nanocomposites for functional applications. Adv. Eng. Mater. 2010, 12, 1177-1190. [CrossRef]

11. Vojtech, L.; Bortel, R.; Neruda, M.; Kozak, M. Wearable textile electrodes for ECG measurement. Adv. Electr. Electron. Eng. 2013, 11, 410-414. [CrossRef]

12. Kumar, P.; Gusain, M.; Nagarajan, R. Synthesis of $\mathrm{Cu}_{1.8} \mathrm{~S}$ and $\mathrm{CuS}$ from copper-thiourea containing precursors; anionic $\left(\mathrm{ClP}^{-}, \mathrm{NO}_{3}{ }^{-}, \mathrm{SO}_{4} \mathrm{P}^{2-} \mathrm{P}\right)$ influence on the product stoichiometry. Inorg. Chem. 2011, 50, 3065-3070. [CrossRef] [PubMed] 
13. Magdassi, S.; Grouchko, M.; Kamyshny, A. Copper nanoparticles for printed electronics: Routes towards achieving oxidation stability. Materials 2010, 3, 4626-4638. [CrossRef] [PubMed]

14. Tursunkulov, O.; Allabergenov, B.; Abidov, A.; Jeong, S.W.; Kim, S. Synthesis, characterization and functionalization of the coated iron oxide nanostructures. J. Korean Powd. Met. Inst. 2013, $20,180$. [CrossRef]

15. Deng, J.; He, C.L.; Peng, Y.; Wang, J.; Long, X.; Li, P.; Chan, A.S.C. Magnetic and conductive $\mathrm{Fe}_{3} \mathrm{O}_{4}{ }^{-}$ polyaniline nanoparticles with core-shell structure. Synth. Met. 2003, 139, 295-301. [CrossRef]

16. Chiu, C.W.; Ou, G.B.; Tsai, Y.H.; Lin, J.J. Immobilization of silver nanoparticles on exfoliated mica nanosheets to form highly conductive nanohybrid films. Nanotechnology 2015, 26, 465702. [CrossRef]

17. Wang, S.; He, M.; Weng, B.; Gan, L.; Zhao, Y.; Xie, Y. Stretchable and wearable triboelectric nanogenerator based on kinesio tape for self-powered human motion sensing. Nanomaterials 2018, 8, 657. [CrossRef]

18. Chiu, C.W.; Lin, C.A.; Hong, P.D. Melt-Spinning and thermal stability behaviour of $\mathrm{TiO}_{2}$ nanoparticle/polypropylene nanocomposite fibers. J. Polym. Res. 2011, 18, 367-372. [CrossRef]

19. Zhang, X.F.; Liu, Z.G.; Shen, W.; Gurunathan, S. Silver nanoparticles: Synthesis, characterization, properties, applications, and therapeutic approaches. Int. J. Mol. Sci. 2016, 17, 1534. [CrossRef]

20. Kholoud, M.M.; Abou, E.N.; Ala, E.; Abdulrhman, A.W. Synthesis and applications of silver nanoparticles. Arabian J. Chem. 2010, 3, 135-140.

21. Chiu, C.W.; Ou, G.B. Facile preparation of highly electrically conductive films of silver nanoparticles finely dispersed in polyisobutylene- $b$-poly(oxyethylene)- $b$-polyisobutylene triblock copolymers and graphene oxide hybrid surfactants. RSC Adv. 2015, 5, 102462-102468. [CrossRef]

22. Dong, R.X.; Liu, C.T.; Huang, K.C.; Chiu, W.Y.; Ho, K.C.; Lin, J.J. Controlling formation of silver/carbon nanotube networks for highly conductive film surface. ACS Appl. Mater. Interfaces 2012, 4, 1449-1455. [CrossRef] [PubMed]

23. Woo, K.; Kim, D.; Kim, J.S.; Lim, S.; Moon, J. Ink-jet printing of Cu-Ag-based highly conductive tracks on a transparent substrate. Langmuir 2009, 25, 429-433. [CrossRef] [PubMed]

24. Jiang, H.; Moon, K.S.; Hua, F.; Wong, C.P. Synthesis and thermal and wetting properties of tin/silver alloy nanoparticles for low melting point lead-free solders. Chem. Mater. 2007, 19, 4482-4485. [CrossRef]

25. Ma, P.C.; Tang, B.Z.; Kim, J.K. Effect of CNT decoration with silver nanoparticles on electrical conductivity of CNT-polymer composite. Carbon 2008, 46, 1497-1505. [CrossRef]

26. Shibata, J.; Shimizu, K.I.; Takada, Y.; Shichi, A.; Yoshida, H.; Satokawa, S.; Satsuma, A.; Hattori, T. Structure of active Ag clusters in Ag zeolites for SCR of NO by propane in the presence of hydrogen. J. Catal. 2004, 227, 367-374. [CrossRef]

27. Aihara, N.; Torigoe, K.; Esumi, K. Preparation and characterization of gold and silver nanoparticles in layered laponite suspensions. Langmuir 1998, 14, 4945-4949. [CrossRef]

28. Liu, J.; Lee, J.B.; Kim, D.H.; Kim, Y. Preparation of high concentration of silver colloidal nanoparticles in layered laponite sol. Colloids Surf. A 2007, 302, 276-279. [CrossRef]

29. Chiu, C.W.; Hong, P.D.; Lin, J.J. Clay-mediated synthesis of silver nanoparticles exhibiting low-temperature melting. Langmuir 2011, 27, 11690-11696. [CrossRef]

30. Chiu, C.W.; Huang, T.K.; Wang, Y.C.; Alamani, B.G.; Lin, J.J. Intercalation strategies in clay/polymer hybrids. Prog. Polym. Sci. 2014, 39, 443-485. [CrossRef]

31. Chiu, C.W.; Chu, C.C.; Dai, S.A.; Lin, J.J. Self-piling silicate rods and dendrites from high aspect-ratio clay platelets. J. Phys. Chem. C 2008, 112, 17940-17944. [CrossRef]

32. Chiu, C.W.; Lin, J.J. Self-assembly behavior of polymer-assisted clay. Prog. Polym. Sci. 2012, 37, 406-444. [CrossRef]

33. Koo, J.H.; Jeong, S.; Shim, H.J.; Son, D.; Kim, J.; Kim, D.C.; Choi, S.; Hong, J.I.; Kim, D.H. Wearable electrocardiogram monitor using carbon nanotube electronics and color-tunable organic light-emitting diodes. ACS Nano 2017, 11, 10032-10041. [CrossRef] [PubMed]

34. Kim, H.W.; Kim, T.Y.; Park, H.K.; You, I.; Kwak, J.; Kim, J.C.; Hwang, H.; Kim, H.S.; Jeong, U. Hygroscopic auxetic on-skin sensors for easy-to-handle repeated daily use. ACS Appl. Mater. Interfaces 2018, 10, 40141-40148. [CrossRef] [PubMed]

(C) 2019 by the authors. Licensee MDPI, Basel, Switzerland. This article is an open access article distributed under the terms and conditions of the Creative Commons Attribution (CC BY) license (http://creativecommons.org/licenses/by/4.0/). 